\title{
Ventral-subgenual anterior cingulate cortex and self-transcendence
}

\author{
Yi-Yuan Tang ${ }^{1,2 *}$ and Rongxiang Tang ${ }^{3}$ \\ ' Department of Psychology, Texas Tech University, Lubbock, TX, USA \\ 2 Department of Psychology, University of Oregon, Eugene, OR, USA \\ ${ }^{3}$ Department of Psychology, The University of Texas at Austin, Austin, TX, USA \\ *Correspondence: yiyuan@uoregon.edu
}

Edited by:

Zoran Josipovic, New York University, USA

Keywords: self-transcendence, altered state of consciousness, anterior cingulate cortex, meditation, integrative body-mind training

Self-transcendence (ST) is one of specific human experiences often related to harmony with nature or feeling oneness with others or the self as an integral part of the whole universe. The Temperament and Character Inventory (TCI) is a widely used personality measure, and ST is one of personality dimensions (Cloninger, 1994; Cloninger et al., 1994). Previous studies showed that ST has significant positive correlation with the sgACC encompassing a ventromedial portion of the prefrontal cortex (vmPFC) using TCI and PET scan (Hakamata et al., 2013). Meanwhile, sgACC/vmPFC activity has been shown to be significantly decreased in patients with anxiety, major depression and mood disorders (Drevets et al., 2008; Shin and Liberzon, 2010; Kühn and Gallinat, 2013). Altogether, these findings suggest that sgACC/vmPFC play an important role in emotion regulation and ST (Hakamata et al., 2013).

ACC as a part of the brain's limbic system, appears active in many neuroimaging studies (Bush et al., 2000; Posner et al., 2007). In general ACC is involved in cognitive (dorsal division) and emotional (ventral/rostral part) processing (Bush et al., 2000). The sensitivity of the ACC to both reward and pain, and evidence for ACC coupling to cognitive and emotional areas during resting state and task performance, support the role of ACC in self-regulation or self-control including emotional, cognitive and autonomic control. Particularly, v/sgACC and adjacent $\mathrm{mPFC}$ area involves in emotional control and autonomic regulation (Luu and Posner, 2003; Posner et al., 2007), consistent with many meditation findings (Hölzel et al., 2011; Tang et al., 2012b; Tang and Posner, 2013).
Meditation often exemplifies positive emotion, pleasant feeling and ST experience in practitioners (Cahn and Polich, 2006; Tang et al., 2007). Studies showed ST is positively related to meditation practice (Levenson et al., 2005). One meditationcategory-automatic self-transcending includes techniques designed to transcend their own activity and improve ST (Travis and Shear, 2010). Substantial evidences indicate that ACC plays a key role in meditation training (Hölzel et al., 2011). For example, compared to non-meditators, long-term Vipassana meditators showed stronger activations in the rostral ACC and adjacent medial PFC bilaterally for the meditation condition (contrasted to arithmetic task). Greater ACC and mPFC activations in meditators may reflect processing of distracting events and emotional processing (Hölzel et al., 2007, 2011). Compared with a memory training control, compassion training elicited activity in a neural network including pregenual ACC, medial orbitofrontal cortex and striatum-brain regions previously associated with positive affect and affiliation (Klimecki et al., 2013a,b). In the same vein, 5 days of one form of meditationintegrative body-mind training (IBMT) improves vACC activity compared to same amount of relaxation training (Tang et al., 2009). Meanwhile, 5 days of IBMT also reduces stress, improves positive emotion and self-report of feeling oneness with nature (Tang et al., 2007). Further, 10 days of IBMT increases white matter connectivity surrounding ACC and this brain structural change correlates with emotional regulation (Tang et al., 2012a,b). These results indicate that meditation accompanies positive emotion, ST experience, and ACC functional and structural changes.
ST related meditation not only induces brain and behavioral changes, it often involves brain (mind) and body cooperation indexed by central (CNS) and autonomic (ANS) nervous system interaction (Cahn and Polich, 2006; Hölzel et al., 2011). Studies have begun to explore interaction and dynamics between CNS and ANS (Critchley et al., 2003; Tang, 2009; Tang and Posner, 2009; Tang et al., 2009; Hölzel et al., 2011; Critchley and Harrison, 2013). For instance, using heart rate variability (HRV), and highand low-frequency power in the cardiac rhythm, ACC activity related to sympathetic modulation of heart rate was observed (Critchley et al., 2003). We measured the physiological and brain changes at rest before, during, and after 5 days of IBMT and relaxation training. During and after training, the IBMT group showed significantly better physiological reactions in heart rate, respiratory amplitude and rate, and skin conductance response (SCR) than the relaxation control. Differences in HRV and EEG power suggested greater involvement of the ANS in the IBMT group during and after training. Imaging data demonstrated stronger v/sgACC activity in the IBMT group. Frontal midline ACC theta was also correlated with high-frequency HRV, suggesting control by the ACC over parasympathetic activity (Tang et al., 2009). These results indicate that brief IBMT induces better regulation of the ANS by a midline v/sg ACC brain system. This changed state probably reflects training in the coordination of body and mind given in the IBMT but not in the relaxation group. These results indicate body-brain works together to maintain certain consciousness states such as ST that may be related to 
different performance (Tang et al., 2007; Xue et al., 2011; Tang et al., 2012a,b). Our findings suggest meditation training could induce altered states of consciousness which may allow us to explore the neuroscience of consciousness based on how alterations in normal consciousness result in functional or/and structural brain changes and plasticity. These alterations in consciousness can affect long-term cognitive, affective and social activities, and may help understand the disease states or disorders of consciousness such as coma, vegetative state, etc. (Tang et al., 2013).

In summary, growing empirical evidences indicate meditation has potential to develop ST-a positive relationship between self and other that transcends self-focused needs and increases prosocial characteristics (Hölzel et al., 2011; Tang et al., 2012a,b; Vago and Silbersweig, 2012). Future studies could examine the relationship between ST and short-term or long-term meditation, and how meditation shapes the perspectives on the self, selfothers, self-nature and its underlying mechanisms using multimodal neuroimaging, physiological, psychosocial and genetic methods.

\section{ACKNOWLEDGMENTS}

We thank Michael Posner's insightful comments. This work was supported by the Office of Naval Research.

\section{REFERENCES}

Bush, G., Luu, P., and Posner, M. I. (2000). Cognitive and emotional influences in anterior cingulate cortex. Trends Cogn. Sci. 4, 215-222. doi: 10.1016/S1364-6613(00)01483-2

Cahn, B. R., and Polich, J. (2006). Meditation states and traits: EEG, ERP, and neuroimaging studies. Psychol. Bull. 132, 180-211. doi: 10.1037/00332909.132.2.180

Cloninger, C. R. (1994). Temperament and personality. Curr. Opin. Neurobiol. 4, 266-273. doi: 10.1016/0959-4388(94)90083-3

Cloninger, C. R., Przybeck, T. R., Svrakic, D. M., and Wetzel, R. D. (1994). The Temperament and Character Inventory (TCI): A Guide to Its Development and Use. St. Louis: Center for Psychobiology of Personality, Washington University at St. Louis.
Critchley, H. D., and Harrison, N. A. (2013). Visceral influences on brain and behavior. Neuron. 77 624-638. doi: 10.1016/j.neuron.2013.02.008

Critchley, H. D., Mathias, C. J., Josephs, O., O'Doherty, J., Zanini, S., Dewar, B. K., et al. (2003). Human cingulate cortex and autonomic control: converging neuroimaging and clinical evidence. Brain. 126(Pt 10), 2139-2152. doi: 10.1093/brain/awg216

Drevets, W., Savitz, J., and Trimble, M. (2008). The subgenual anterior cingulate cortex in mood disorders. CNS Spectr. 13, 663-681.

Hakamata, Y., Iwase, M., Kato, T., Senda, K., and Inada, T. (2013). The neural correlates of mindful awareness: a possible buffering effect on anxietyrelated reduction in subgenual anterior cingulate cortex activity. PLoS ONE 8:e75526. doi: 10.1371/journal.pone.0075526

Hölzel, B. K., Lazar, S. W., Gard, T., Schuman-Olivier, Z., Vago, D. R., and Ott, U. (2011). How does mindfulness meditation work? Proposing mechanisms of action from a conceptual and neural perspective. Perspect. Psychol. Sci. 6, 537-559. doi: 10.1177/1745691611419671

Hölzel, B. K., Ott, U., Hempel, H., Hackl, A., Wolf, K., Stark, R., et al. (2007). Differential engagement of anterior cingulate and adjacent medial frontal cortex in adept meditators and non-meditators. Neurosci Lett. 421, 16-21. doi: 10.1016/j.neulet.2007.04.074

Klimecki, O. M., Leiberg, S., Lamm, C., and Singer, T. (2013a). Functional neural plasticity and associated changes in positive affect after compassion training. Cereb Cortex. 23, 1552-1561. doi: $10.1093 /$ cercor/bhs 142

Klimecki, O. M., Leiberg, S., Ricard, M., and Singer, T. (2013b). Differential pattern of functional brain plasticity after compassion and empathy training. Soc. Cogn. Affect. Neurosci. doi: 10.1093/scan/nst060. [Epub ahead of print].

Kühn, S., and Gallinat, J. (2013). Resting-state brain activity in schizophrenia and major depression: a quantitative meta-analysis. Schizophr. Bull. 39, 358-365. doi: 10.1093/schbul/sbr151

Levenson, M. R., Jennings, P. A., Aldwin, C. M., and Shiraishi, R. W. (2005). Self-transcendence: conceptualization and measurement. Int J Aging Hum Dev. 60(2):127-143 doi: 10.2190/XRXM-FYRA7U0X-GRC0

Luu, P., and Posner, M. I. (2003). Anterior cingulate cortex regulation of sympathetic activity. Brain. 126(Pt 10), 2119-2120. doi: 10.1093/brain/awg257

Posner, M. I., Sheese, B., Rothbart, M., and Tang, Y. Y. (2007). The anterior cingulate gyrus and the mechanism of self-regulation. Cogn Affect Behav Neurosci. 7, 391-395 doi: 10.3758/CABN.7.4.391

Shin, L., and Liberzon, I. (2010). The neurocircuitry of fear, stress, and anxiety disorders. Neuropsychopharmacology 35, 169-191. doi: 10.1038/npp. 2009.83

Tang, Y. Y. (2009). Exploring the Brain, Optimizing the Life. Beijing: Science Press.
Tang, Y. Y., Lu, Q., Fan, M., Yang, Y., and Posner. M. I. (2012a). Mechanisms of white matter changes induced by meditation. Proc. Natl. Acad. Sci. U.S.A 109, 10570-10574. doi: 10.1073/pnas.1207817109

Tang, Y. Y., Rothbart, M. K., and Posner, M. I. (2012b). Neural correlates of establishing maintaining and switching brain states. Trends Cogn. Sci. 16, 330-337. doi: 10.1016/j.tics.2012.05.001

Tang, Y. Y., Ma, Y., Fan, Y., Feng, H., Wang, J., Feng, S., et al. (2009). Central and autonomic nervous system interaction is altered by short-term meditation. Proc. Natl. Acad. Sci. U.S.A. 106, 8865-8870. doi: 10.1073/pnas.0904031106

Tang, Y. Y., Ma, Y., Wang, J., Fan, Y., Feng, S., Lu, Q., et al. (2007). Short-term meditation training improves attention and self-regulation. Proc. Natl. Acad. Sci. U.S.A. 104, 17152-17156. doi: 10.1073/pnas.0707678104

Tang, Y. Y., and Posner, M. I. (2009). Attention training and attention state training. Trends Cogn. Sci. 13, 222-227. doi: 10.1016/j.tics.2009.01.009

Tang, Y. Y., and Posner, M. I. (2013). Tools of the trade: Theory and method in mindfulness neuroscience. Soc. Cogn. Affect. Neurosci. 8, 118-120. doi: 10.1093/scan/nss 112

Tang, Y. Y., Posner, M. I., and Rothbart, M. K. (2013). Meditation improves self-regulation over the life span. Ann. N.Y. Acad. Sci. doi: 10.1111/nyas.12227. [Epub ahead of print].

Travis, F., and Shear, J. (2010). Focused attention, open monitoring and automatic self-transcending: Categories to organize meditations from Vedic, Buddhist and Chinese traditions. Conscious Cogn. 19, 1110-1118. doi: 10.1016/j.concog.2010.01.007

Vago, D. R., and Silbersweig, D. A. (2012). Selfawareness, self-regulation, and self-transcendence (S-ART): a framework for understanding the neurobiological mechanisms of mindfulness. Front. Hum. Neurosci. 6:296. doi: 10.3389/fnhum.2012.00296

Xue, S., Tang, Y. Y., and Posner, M. I. (2011). Shortterm meditation increases network efficiency of the anterior cingulate cortex. Neuroreport 22, 570-574. doi: 10.1097/WNR.0b013e328348c750

Received: 28 November 2013; accepted: 15 December 2013; published online: 27 December 2013.

Citation: Tang $Y-Y$ and Tang $R$ (2013) Ventral-subgenual anterior cingulate cortex and self-transcendence. Front. Psychol. 4:1000. doi: 10.3389/ fpsyg.2013.01000

This article was submitted to Consciousness Research, a section of the journal Frontiers in Psychology.

Copyright (c) 2013 Tang and Tang. This is an openaccess article distributed under the terms of the Creative Commons Attribution License (CC BY). The use, distribution or reproduction in other forums is permitted, provided the original author(s) or licensor are credited and that the original publication in this journal is cited, in accordance with accepted academic practice. No use, distribution or reproduction is permitted which does not comply with these terms. 